\title{
USE OF HYDRAULIC PHENOMENA IN ENHANCEMENT OF DISSOLVED OXYGEN CONCENTRATION
}

\author{
Rajkumar V. Raikar ${ }^{1}$, Poornima B. Kamatagi ${ }^{2}$ \\ ${ }^{I}$ Professor, Department of Civil Engineering, KLE Dr. M. S. Sheshgiri College of Engineering and Technology, \\ Belgaum, Karnataka, India \\ ${ }^{2}$ M.Tech Scholar, Department of Civil Engineering, KLE Dr. M. S. Sheshgiri College of Engineering and Technology, \\ Belgaum, Karnataka, India
}

\begin{abstract}
The dissolved oxygen (DO) content of water bodies is an indicator of water quality and hence a measure of ability of water to sustain aquatic life. Hydraulic phenomena such as hydraulic drops and hydraulic jumps can increase the amount of DO in the water by creating turbulent conditions. The main reason for this oxygen transfer is the air entrainment into the flow through large number of air bubbles that helps in air-water transfer. The present study investigates the effect of different weir types and hydraulic jump on their aeration efficiency. Two types of weirs namely rectangular and triangular weirs were used in the study. Also, the hydraulic jump was studied as an aeration agent. From the experimental results, it was found that the triangular weir provides greater aeration efficiency of 0.1948 as compared with rectangular weir that had aeration efficiency of 0.1012. On the other hand, the hydraulic jump showed aeration efficiency of 0.14285. As the weirs are more efficient than hydraulic jump, they are most applicable in the field. Also, weir structures are less expensive when compared with the structural arrangement required for the formation of hydraulic jump.
\end{abstract}

Keywords: Dissolved oxygen, Aeration efficiency, Weir, Hydraulic jump

\section{INTRODUCTION}

Dissolved oxygen (DO) is very essential to healthy rivers, streams and lakes. Many naturally occurring biological and chemical processes use oxygen, thereby decreasing the DO concentration in water and causing greater stress. The aeration process replenishes the oxygen [1]. However, aeration can be enhanced by modifying the flow pattern through phenomena like hydraulic jump and hydraulic drop. Hydraulic structures have an impact in enhancing the amount of dissolved oxygen in a river system, even though the water is in contact with the structure for only a short time. The same quantity of oxygen transfer that normally would occur over several kilometers in a river can occur at a single hydraulic structure. The primary reason for this accelerated oxygen transfer is entrainment of air into the flow due to large number of bubbles. These air bubbles greatly increase the surface area available for mass transfer [2]. The most classic example of hydraulic structure where gas transfer occurs is a weir. Weir aeration occurs in rivers, fish hatcheries and water treatment plants. The available hydraulic head can easily be used for aeration and also no operating cost incurs in the process as compared to other artificial aerators. Another example where aeration occurs is the hydraulic jump. Aeration by hydraulic jump is troublefree and cost-effective way to achieve oxygen transfer than conventional oxygenation systems. Hydraulic jump develops large-scale turbulence, surface waves and spray. Further it dissipates energy and ensures the entrainment of air into water. Hydraulic jumps in the streams increase the amount of DO even though the water stays at short interval of time in the self-aeration process. Several studies have been carried out to investigate the self-aeration characteristic of hydraulic jumps [3, 4, 5]. Chanson [3] studied aeration efficiency of hydraulic jump, while Apted [4] carried out experiments with hydraulic jump formed in the narrowed section of a flume downstream of an underflow sluice gate. Generally, self-aeration capability of hydraulic jump is expressed in terms of aeration efficiency. Avery and Novak [5] formulated expression of efficiency of aeration at jump using upstream Froude number and Reynolds number. Willhelms et al. [6] presented similar expression as that of Avery and Novak [5]. Kucukali and Cokgor [7] developed a fuzzy logic model to predict hydraulic jump aeration efficiency based on experimental data. Based on the previous investigations, it is observed that the comparative study on the aeration efficiency of both hydraulic structures like weirs and hydraulic jump is not studied. Hence, the present study undertakes the comparative study on aeration efficiency of one hydraulic drop downstream of a weir and hydraulic jump.

\section{EXPERIMENTATION}

\subsection{Testing Facilities}

The experiments were carried out in a recirculating tilting flume at the Fluid Mechnics Laboratory of Department of Civil Engineering, KLE Dr. M. S. Sheshgiri College of Engineering and Technology, Belgaum. The dimensions of the flume were $0.15 \mathrm{~m}$ width, $0.15 \mathrm{~m}$ depth and $3 \mathrm{~m}$ length having the maximum flow rate of 5.3 liter/sec. The channel consisted of a $1.1 \mathrm{~kW}$ centrifugal pump, which facilitated the recirculation of flow. The water from the channel is 
plunged into downstream water pool. The water from the downstream water pool was transferred into another tank in which the chemicals were mixed so as to make dissolved oxygen (DO) of water as zero. From chemical mixing tank, water enters channel through head box containing screen, which facilitated in flow smoothening and reducing flow irregularities. The inflow of the water was controlled using the gate provided at upstream of the flume. Dissolved oxygen was measured using DO meter having measurement range of 0 to $20 \mathrm{ppm}$ and temperature $5^{\circ}$ to $50^{\circ} \mathrm{C}$. For experimentation with weir aeration, the weir models were fitted at the downstream end of the experimental channel with proper fixing arrangement. However, for experiments with hydraulic jump aeration, the gates provided on upstream and downstream sides of the experimental channel were used to form the hydraulic jump. Rectangular and triangular weir models were fabricated according to the flume dimensions using acrylic sheets of $5 \mathrm{~mm}$ thickness. Each weir was tested under flow rate $Q$ varying from 0.5 to 2 liter/sec. The drop height $h$, defined as the depth of water level in the downstream water pool below the weir crest was varied in the range of 15 to $45 \mathrm{~cm}$.

\subsection{Experimental Procedure for Weir Aeration}

Each experimental run was started by filling the chemical mixing tank with clean water in which sodium sulphite $\left(\mathrm{Na}_{2} \mathrm{SO}_{3}\right)$ and cobalt chloride $\left(\mathrm{CoCl}_{2}\right)$ were added to the water in suitable amounts corresponding to the volume of available water and mixed thoroughly to reduce DO concentration to $0 \mathrm{mg} / \mathrm{l}$. The water was fed into the flume by a centrifugal pump from the chemical mixing tank and the water falling from the weir was allowed to fall into downstream water pool, where water level was varied to create different drop heights. DO concentration was measured using DO meter on upstream side of weir model and in the downstream water pool. DO meter was calibrated prior to use by using standard procedure. DO measurements were done at four different sampling points and temperature measurement was also done simultaneously during sampling. Four runs were conducted for each weir by varying the flow rate from 0.5 to $2 \mathrm{l} / \mathrm{s}$ in $0.5 \mathrm{l} / \mathrm{s}$ steps. Drop height was varied from $15 \mathrm{~cm}$ to $45 \mathrm{~cm}$ in $10 \mathrm{~cm}$ step by varying water level in the downstream water pool.

\subsection{Experimental Procedure for Hydraulic Jump}

\section{Aeration}

Experiments were carried out with three pre-jump flow depths $\mathrm{y}_{1}$ of $1 \mathrm{~cm}, 1.5 \mathrm{~cm}$ and $2 \mathrm{~cm}$. The downstream gate was used to form clear jumps in the test section. The flow rate was varied using the valve. The approaching flow Froude numbers $F_{1}\left(=V_{1}^{2} / \sqrt{g y_{1}}\right.$, where $V_{1}=$ approaching flow velocity $=Q / b y_{1}, b=$ width of channel and $\mathrm{g}=$ acceleration due to gravity) were in the range of 1.88 to 4.78. The upstream side gate was fixed to pre-determined opening and water is allowed to flow from chemical mixing tank. The flow rate was adjusted using the control valve. Then the downstream end gate was adjusted to create the hydraulic jump. After the hydraulic jump occupies the steady position, the DO measurements were done before and after the jump using DO meter. Also the temperature was measured. The aeration efficiency $E=\frac{C_{d d}-C_{u}}{C_{g}-C_{u}}=1-\frac{1}{r}$ was computed, where $\mathrm{C}_{\mathrm{d}}=$ downstream (DO) concentration in $\mathrm{mg} / \mathrm{l}, \mathrm{C}_{\mathrm{u}}=$ upstream (DO) concentration in $\mathrm{mg} / \mathrm{l}, \mathrm{C}_{\mathrm{s}}=$ saturation concentration in $\mathrm{mg} / \mathrm{l}$ and $\mathrm{r}=$ oxygen deficit ratio. Further, the aeration efficiency at $20^{\circ} \mathrm{C}\left(\mathrm{E}_{20}\right)$ was determined using $1-\mathrm{E}_{20}=(1-E)^{1 / f}$ where $\mathrm{f}$ is exponent given by $f$ $=1.0+0.02103(T-20)+8.261 \times 10^{-5}(T-20)^{2}$.

\section{RESULTS AND DISCUSSIONS}

\subsection{Experimental Results with Rectangular Weir}

The experimental results were obtained using rectangular weir with flow rate $Q$ varying from 0.5 to $21 / \mathrm{s}$ and drop height $h$ in the range $15 \mathrm{~cm}$ to $45 \mathrm{~cm}$. Oxygen transfer that occurs at weir is sensitive to water temperature and hence temperature correction factor has been used. The variation of aeration efficiency with drop height shown in Fig. 1 (a), which shows that the aeration efficiency increases with an increase in drop height and discharge rate. For a given discharge, the aeration efficiency increases with increase in drop height and for a particular drop height the efficiency of rectangular weir increases with increase in discharge. The maximum aeration efficiency of rectangular weir was found to be 0.1012 at 2 1/s discharge and drop height of $45 \mathrm{~cm}$. It is found that the drop height and discharge play very important role in oxygen transfer. Similar results were also reported by Baylar and Bagatur [2]. The variation of aeration efficiency at $20^{\circ} \mathrm{C}$ with drop height is shown in Fig 1 (b). The maximum aeration efficiency at $20^{\circ} \mathrm{C}$ is found to be 0.0877 with drop height of $45 \mathrm{~cm}$ under flow rate of $2 \mathrm{l} / \mathrm{s}$. 


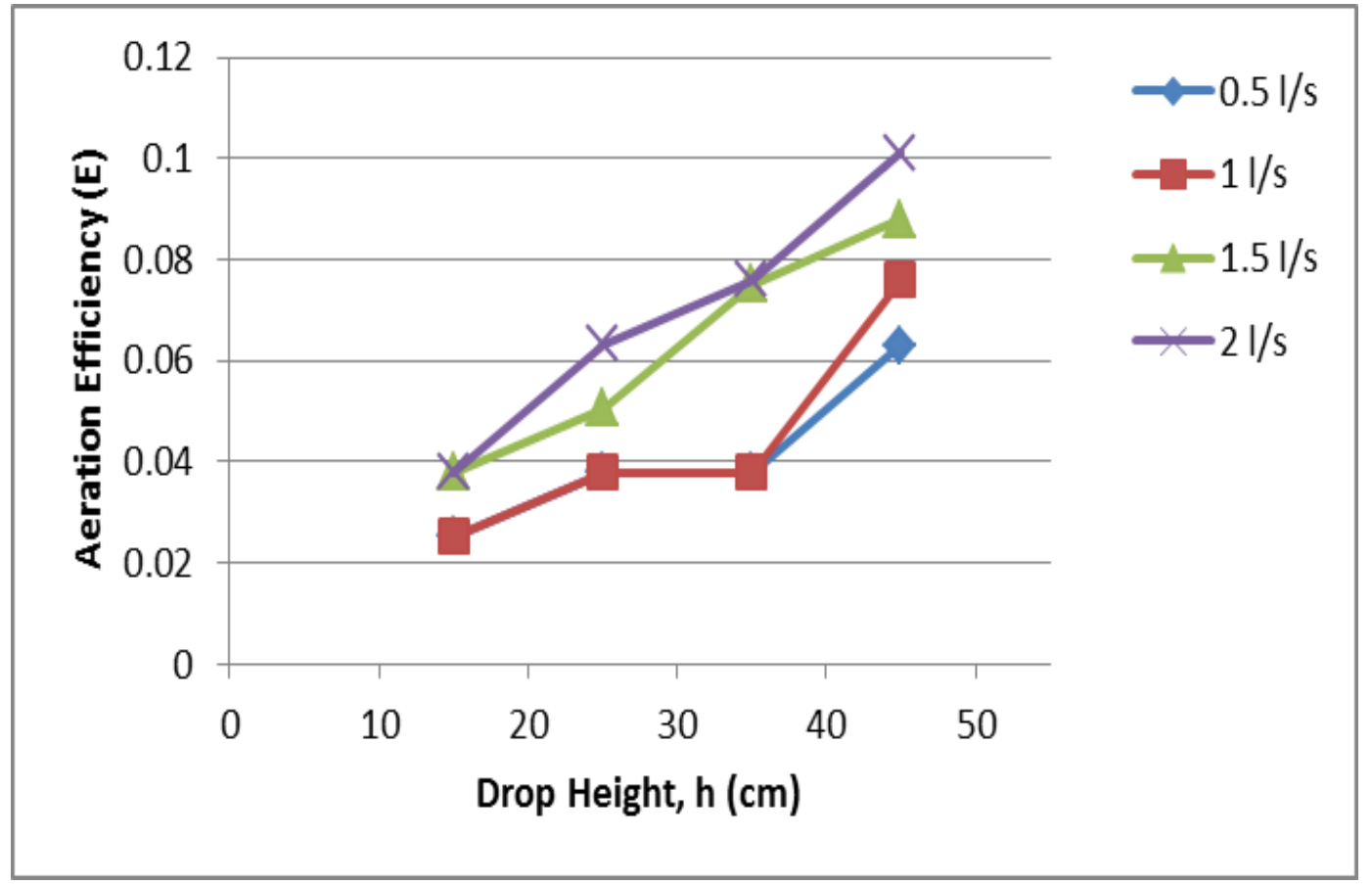

(a)

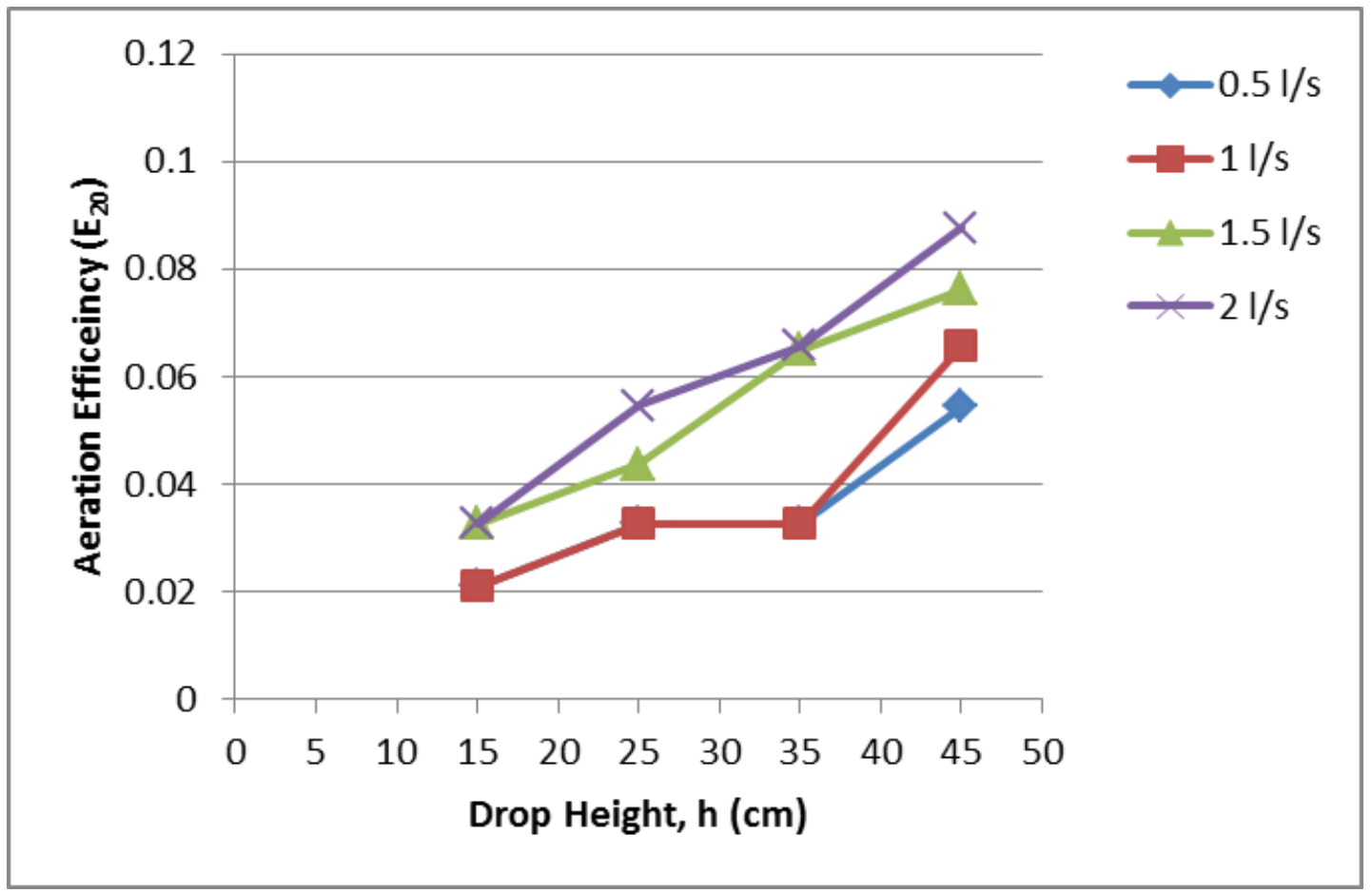

(b)

Fig -1: Variation of aeration efficiency with drop height and discharge for rectangular weir: (a) at room temperature and (b) at $20^{\circ} \mathrm{C}$

\subsection{Experimental Results with Triangular Weir}

The aeration experiments with $90^{\circ}$ triangular weir were carried out with $Q$ ranging from 0.5 to $21 / \mathrm{s}$. The maximum aeration efficiency $\mathrm{E}$ at room temperature was found to be 0.1948 at $2 \mathrm{l} / \mathrm{s}$ discharge with $45 \mathrm{~cm}$ drop height. On the other hand, the corresponding maximum aeration efficiency at $20^{\circ} \mathrm{C}\left(\mathrm{E}_{20}\right)$ was 0.1656 for $2 \mathrm{l} / \mathrm{s}$ discharge. Figs. 2 (a) and
2 (b) demonstrate the variation of aeration efficiencies under room temperature $(\mathrm{E})$ and at $20^{\circ} \mathrm{C}\left(\mathrm{E}_{20}\right)$ with drop height and discharge for triangular weir. Similar to rectangular weir, the aeration efficiency increases with increase in drop height for a discharge and also for a particular drop height the aeration efficiency increases with an increase in discharge. 


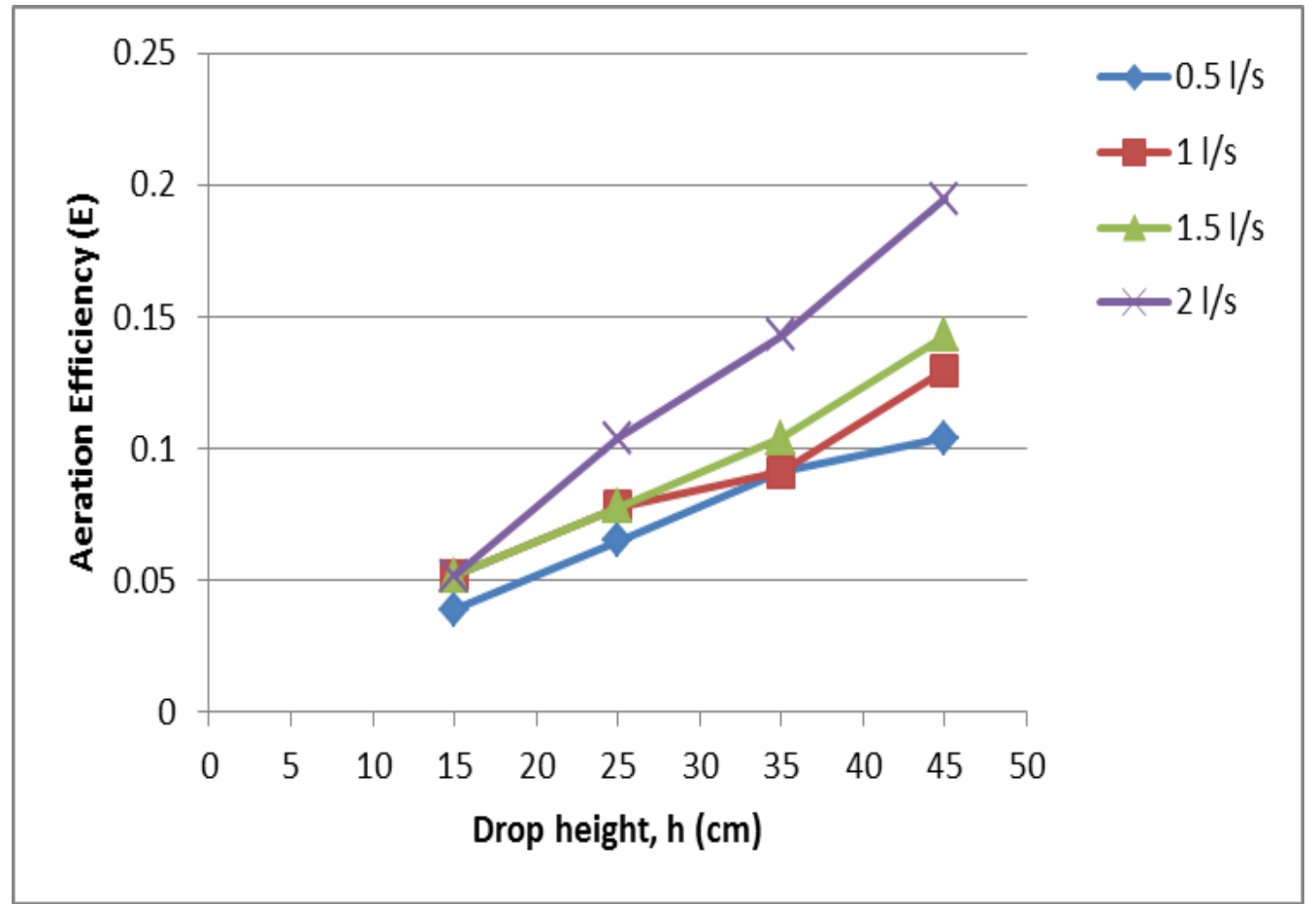

(a)

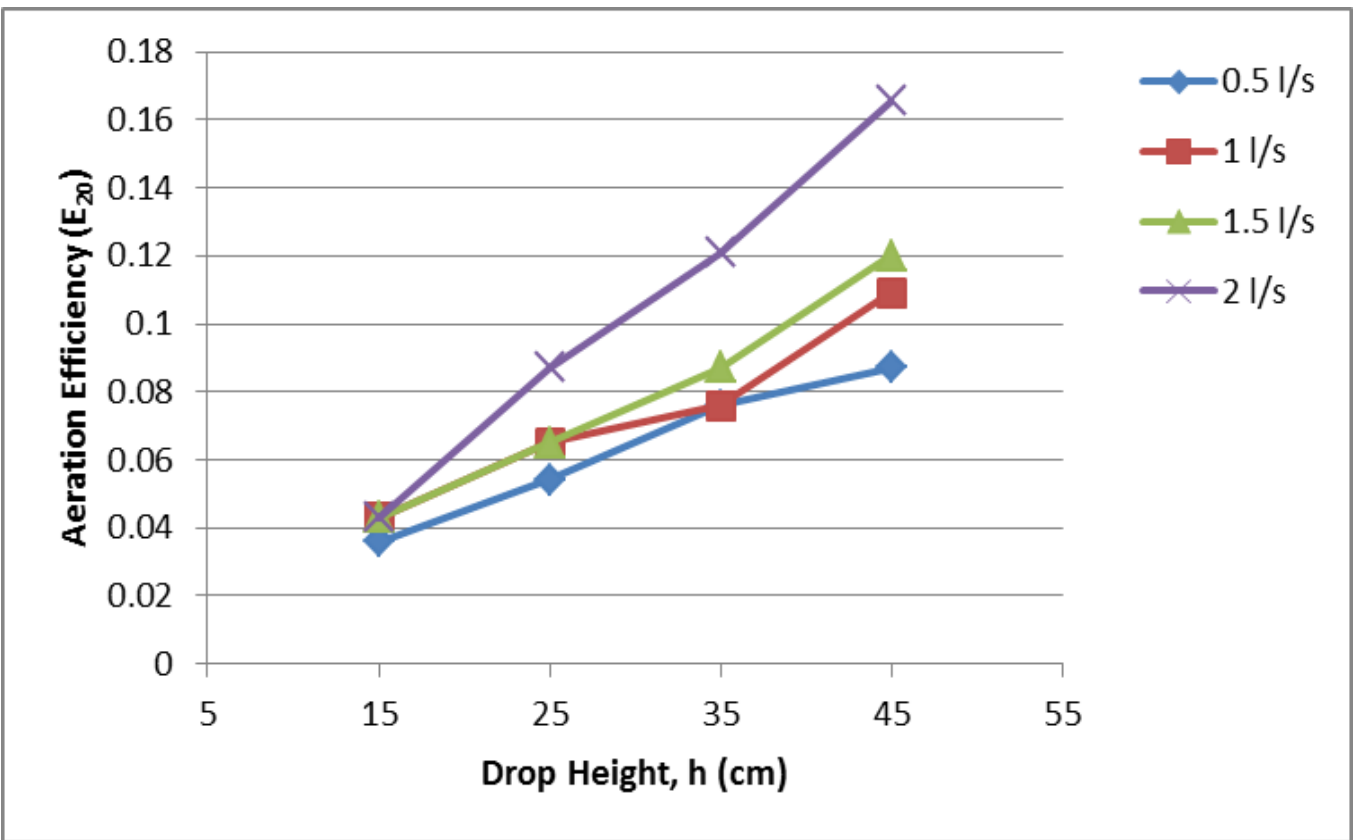

(b)

Fig -2: Variation of aeration efficiency with drop height and discharge for triangular weir: (a) at room temperature and (b) at $20^{\circ} \mathrm{C}$

\subsection{Comparison of Aeration Efficiency with}

\section{Rectangular and Triangular Weirs}

In this section the comparison between aeration efficiency of rectangular and triangular weirs is discussed. Figs. 3 (a-d) illustrate the comparison of aeration efficiency of rectangular and triangular weirs with drop heights $(15 \mathrm{~cm}$ to $45 \mathrm{~cm}$ ) and discharge rate $0.5 \mathrm{l} / \mathrm{s}$ to $2 \mathrm{l} / \mathrm{s}$, respectively. From these figures it can be concluded that triangular weir had greater aeration efficiency than rectangular weir for all cases. This is due to larger air entrainment and turbulent mixing of the falling nappe of triangular weir. This corroborates with the results of Baylar and Bagatur [2]. Maximum efficiency of triangular weir is 0.1948 at $2 \mathrm{l} / \mathrm{s}$ discharge and $45 \mathrm{~cm}$ drop height while that of rectangular weir is 0.1012 with same discharge and drop height. The $90^{\circ}$ triangular weir had greater aeration efficiency because of larger air entrainment and turbulent mixing due to shape of the jet causing higher oxygen transfer. 


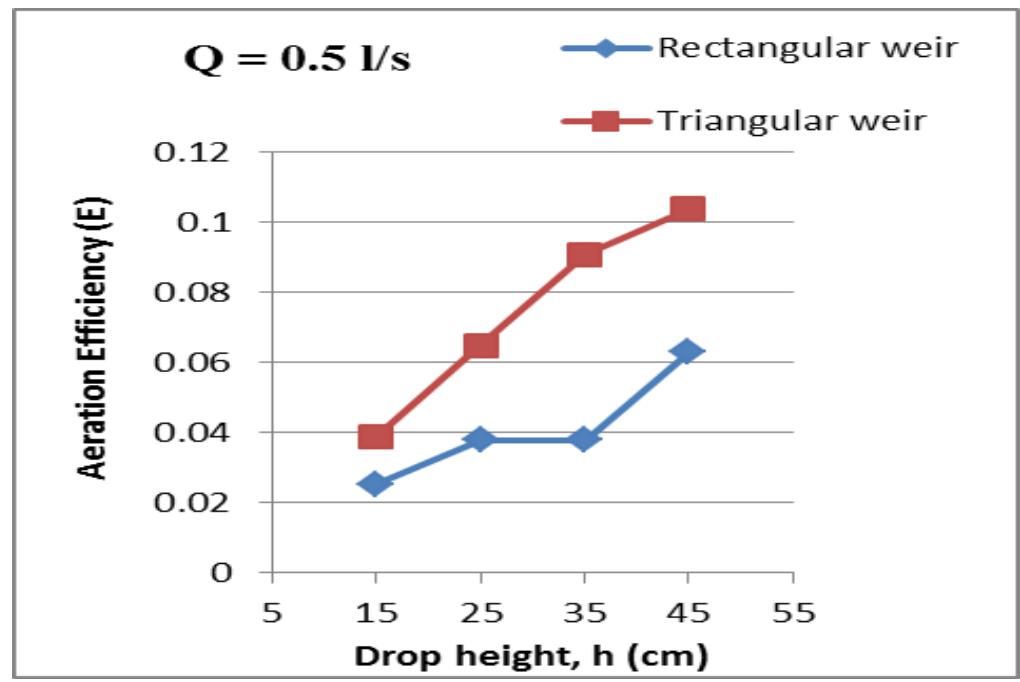

(a)

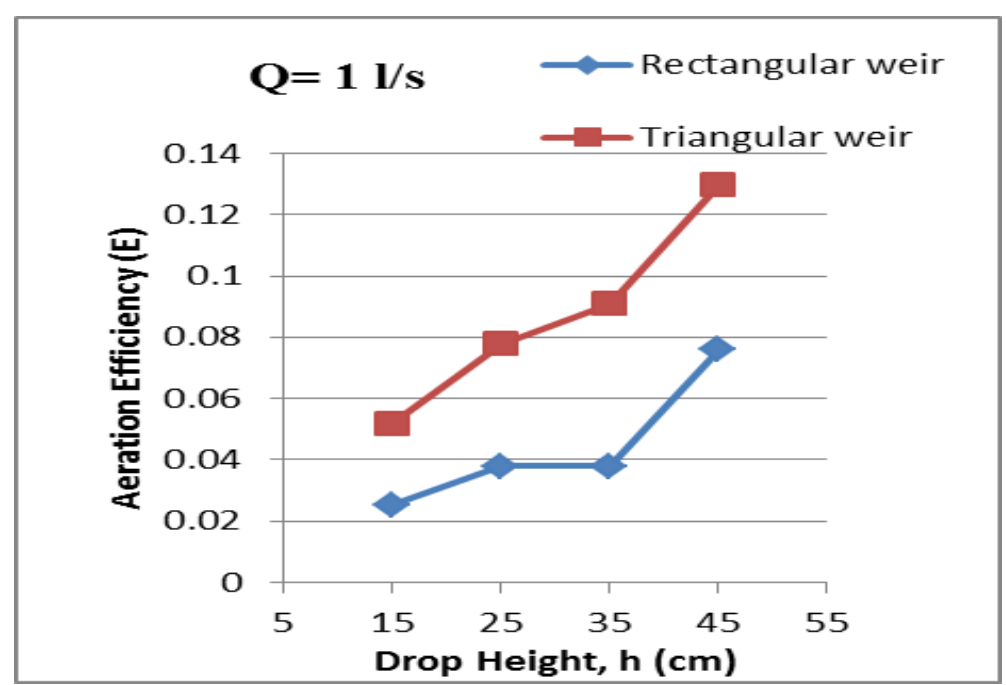

(b)

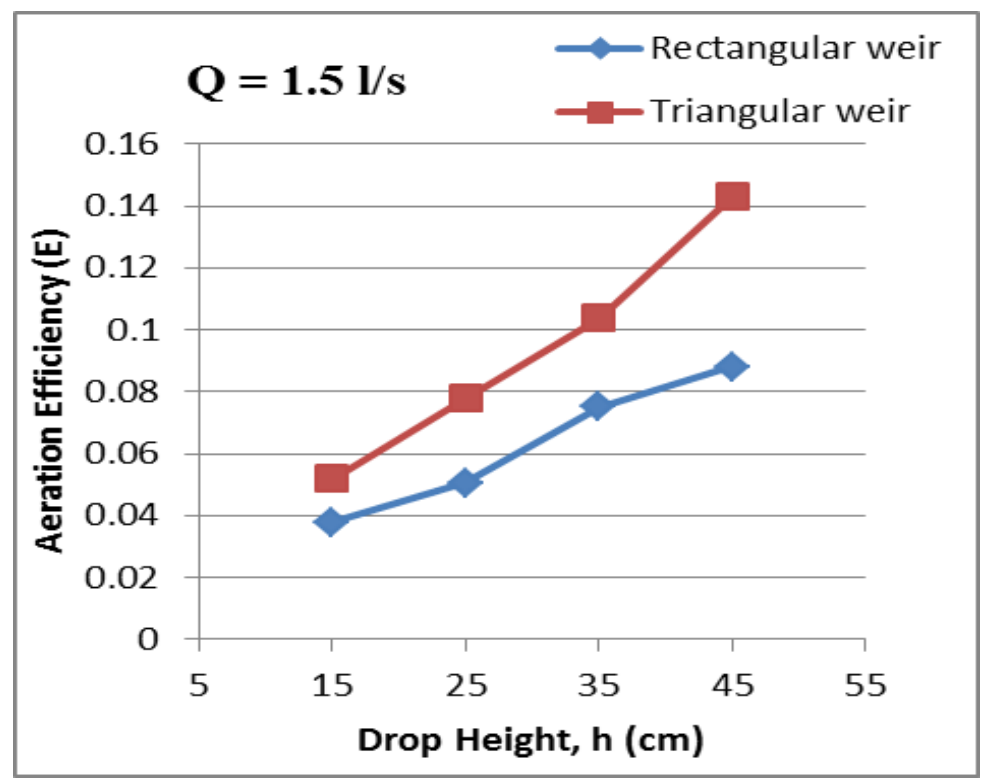

(c) 


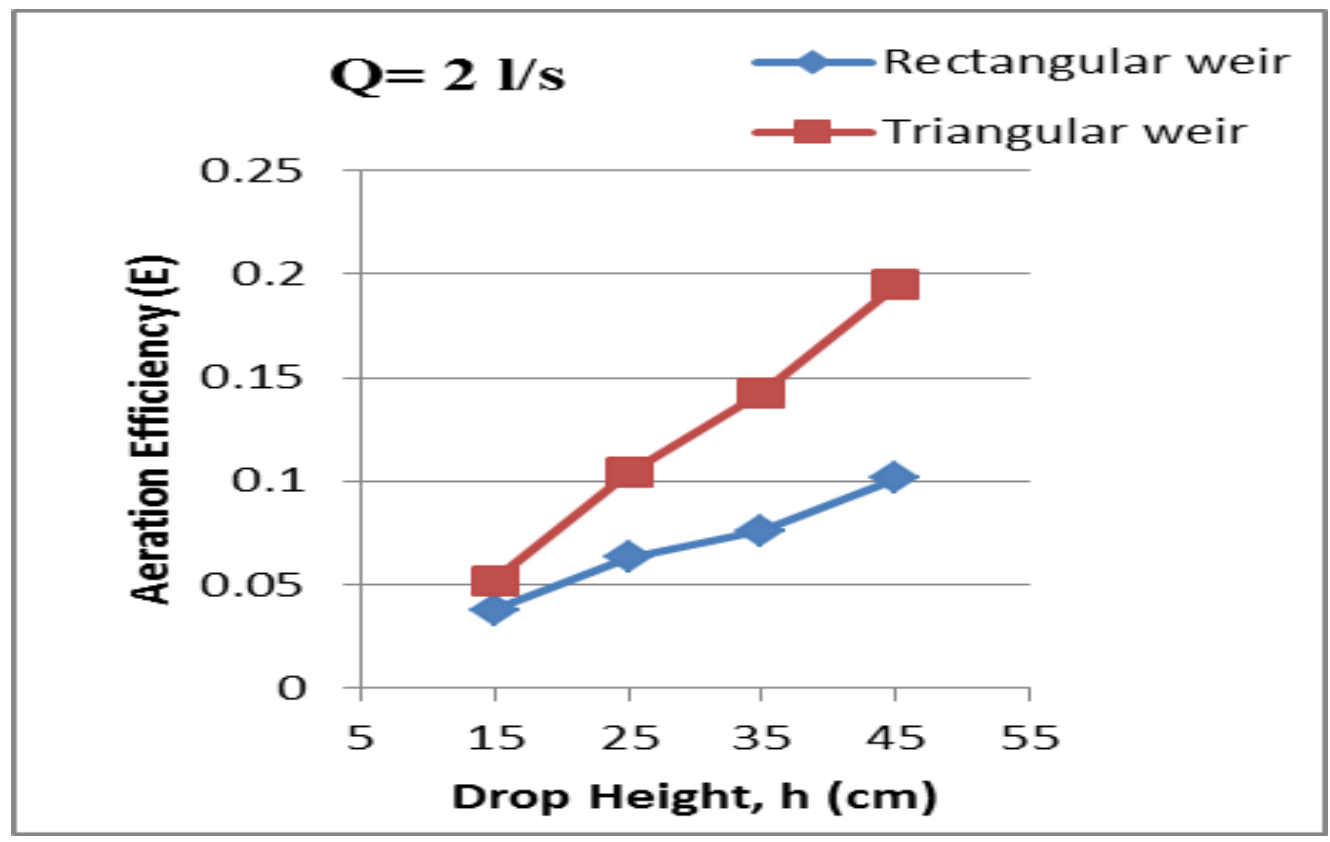

(d)

Fig -3: Comparison of aeration efficiencies $E$ of rectangular and triangular weirs for: (a) $Q=0.5 \mathrm{l} / \mathrm{s}$, (b) $Q=1 \mathrm{l} / \mathrm{s}$, (c) $\mathrm{Q}=1.5 \mathrm{l} / \mathrm{s}$, (d) $Q=21 / s$

\subsection{Experimental Results using Hydraulic Jump}

In this section, results on aeration efficiency of hydraulic jump are presented. Approaching flow Froude number $F_{1}$ was varied in the range from 1.88 to 4.78 . The experiments were carried with different approaching depths $y_{1}=1 \mathrm{~cm}$, $1.5 \mathrm{~cm}$ and $2 \mathrm{~cm}$. Temperature was also measured during experimentation and recorded.
Fig. 4 depict the variation of aeration efficiency $E$ with approaching flow Froude number $F_{1}$ for pre-jump depth $y_{1}$ values of $2 \mathrm{~cm}, 1.5 \mathrm{~cm}$ and $1 \mathrm{~cm}$. From figures it is observed that with increase in approaching flow Froude number $F_{1}$ the aeration efficiency enhances. This is due to larger turbulence and bubble generation which result into more air entrainment, particularly for Froude numbers from 2 to 4. Bostan et al. [8] reported similar results. In the present study, the maximum aeration efficiency $\mathrm{E}=0.14285$ is obtained for $F_{1}=2.63$ with $y_{1}=2 \mathrm{~cm}$ and the corresponding value of $\mathrm{E}_{20}$ (at $20^{\circ} \mathrm{C}$ ) was found to be 0.121 .

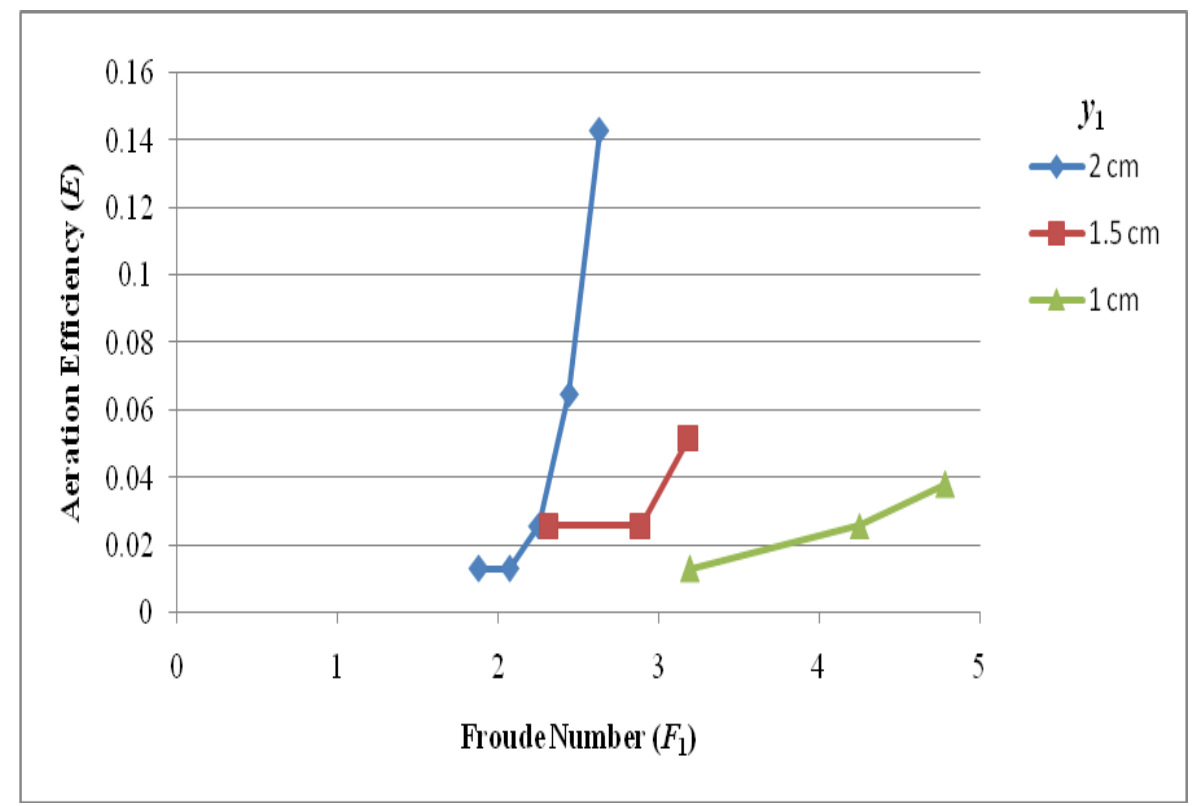

Fig -4: Variation of aeration efficiency $E$ with approaching Froude number $F_{1}$ 


\subsection{Comparison of Aeration Efficiency of Weir and}

\section{Hydraulic Jump}

From the experimental results obtained it is concluded that aeration efficiency of weirs is more than the hydraulic jump aeration. The maximum aeration efficiency in case of hydraulic jump is found to be 0.14285 , while that with rectangular and triangular weirs it is 0.1012 and 0.1948 . In weir aeration the drop height plays a very important role that enhances aeration as compared with hydraulic jump. In general, the weir structures increase the contact time of between water and air and hence aeration rate increases. Further, the jet impact on the downstream side also enhances the bubble generation and increases the aeration rate. On the other hand, in case of hydraulic jump, only the turbulence created during the jump occurrence at vorticity region enhances the air entrainment. In addition, in the field, the construction of hydraulic drops in the form of series of small check dams would facilitate drop structures. On the other hand, creation of hydraulic jump requires construction of apron and other appurtenances. From this point of view, weirs are preferred as compared with hydraulic jump.

\section{CONCLUSION}

Following conclusions are drawn from the laboratory experimental study:

1. The drop height was considered to be most important parameter influencing oxygen transfer of weirs. The aeration efficiency increased with an increase in drop height for both types of weir. The maximum aeration efficiency is found for the drop height of $45 \mathrm{~cm}$.

2. Aeration efficiency increased with an increase in discharge. Increased discharge leads to greater oxygen transfer efficiency.

3. Temperature also plays very important role in oxygen transfer.

4. The aeration efficiency is greater for $90^{\circ}$ triangular weir as compared with rectangular weir. The maximum aeration efficiency with rectangular weir is found to be 0.1012 while with $90^{\circ}$ triangular weir it is 0.1948 at $2 \mathrm{l} / \mathrm{s}$ discharge and drop height of 45 $\mathrm{cm}$. Hence, triangular weirs are recommended for aeration processes.

5. In case of hydraulic jump, the aeration efficiency increases with an increase in jump height, approaching flow Froude number and energy loss. The maximum aeration efficiency is found as 0.14285 for $4.7 \mathrm{~cm}$ jump height, approaching flow Froude number 2.63 and energy loss of $1.936 \mathrm{~cm}$.

6. As compared to hydraulic jump, the weirs are found to be more efficient in aeration. In addition, the weir structures are preferred to hydraulic jump in the field as they are easy to provide in the form of series of small check dams, while aprons with appurtenances are to be constructed for creating hydraulic jump. Hence, weir structures are less expensive than hydraulic.

\section{REFERENCES}

[1]. Baylar, A., Emiroglu, M. E. An experimental study of air entrainment and oxygen transfer at a water jet from a nozzle with air holes, Water Environment Research, Vol. 76(3), 2004, pp. 231-7.

[2]. Baylar, A., and Bagatur, T., Aeration Performance of Weirs, Water SA Vol. 26(4), October 2000.

[3]. Chanson, H., Predicting Oxygen Content Downstream of Weirs, Spillways and Waterways, Proc Instn Civ. Engrs Wat. Marit and Energy UK, Vol. 112, 1995, pp. 20-30.

[4]. Apted, R. W., The mechanics of aeration at weirs with special reference to river quality, M.Sc. thesis, University of Newcastle, 1975.

[5]. Avery, S. T., and Novak, p., Oxygen Transfer at Hydraulic Structures, Journal of Hydraulics Division, ASCE, Vol. 104, 1978, pp. 1521-1540.

[6]. Wilhelms, S. C., and Smith, D. R., Reaeration through Gated Conduit Outlet Works, Technical Report US Army of Corps of Engineers, Waterways Experiment Station, Vicksburg, MS E-81-5 March (1981).

[7]. Kucukali, S., and Cokgor, S., Fuzzy Logic Model to Predict Hydraulic Jump Aeration Efficiency, Proceedings of the ICE Water Management Vol. 160(4), 2007, pp. 225-231. [8]. Bostan, T., Cosar, A., Yetilmezsoy, K., Topcu, S., and Agaccioglu, H., The Effect of Hydraulic Jump on the Aeration Efficiency, 2nd International Balkans Conference on Challenges of Civil Engineering (BCCE), Epoka University, Tirana Albania, 23-25 May, 2013 